\title{
A Cross-Institutional Ethnographic Project: Mapping Play in Intercultural Communities
}

\author{
Akosua Obuo Addo ${ }^{1} \&$ Eric E. Castle ${ }^{2}$ \\ ${ }^{1}$ School of Music, University of Minnesota, Minneapolis, USA \\ ${ }^{2}$ Agriculture and Natural Resources Department, University of Minnesota Crookston, MN, USA \\ Correspondence: Eric E. Castle, Agriculture and Natural Resources Department, University of \\ Minnesota-Crookston, Crookston, MN, USA. Tel: 1-218-281-8119. E-mail: cast1047@crk.umn.edu \\ Received: October 17, 2014 \\ Accepted: December 5, $2014 \quad$ Online Published: January 21, 2015 \\ doi:10.5539/hes.v5n1p1 \\ URL: http://dx.doi.org/10.5539/hes.v5n1p1
}

\begin{abstract}
Curricula content and structure that encourages interdisciplinary learning, inter-level organization, cross-institutional study supports innovation and inspires new ideas about curricular design in higher education. The purpose of this article is to discuss a collaborative effort of two classes on different campuses to map play in the culturally diverse Cedar-Riverside neighborhood of the Twin Cities. Using technology to create geospatially situated digital visual stories about play was an effective mechanism for facilitating interdisciplinary learning, ethics, learner autonomy and dialogue. Cross-institutional pedagogical strategies shifted as we adjusted to the realities of the physical space, weather conditions, ethical and intercultural considerations.
\end{abstract}

Keywords: cross-institutional collaboration, play, culture interdisciplinary learning, mapping

\section{Introduction and Literature Review}

\subsection{Technology in Cross-Institutional Curriculum Design in Higher Education}

Higher education institutions have long sought to keep abreast with changing society through curriculum innovation, in content and course structure. Technology has played a major role in curriculum innovation. Thus, research on the role of technology in higher education curricula innovation is extensive (Duin, Anklesaria, \& Nater, 2012). One of the recommendations of the 1997 report on the technology reform in higher education was to make collaboration and cooperation the institutional focus (Van Dusen, 1997). Van Dusen placed an emphasis on virtual learning spaces created in the "convergence of ... technologies including, but not restricted to, the Internet, World Wide Web, computer-mediated communication, video conferencing, multimedia, groupware, video- on-demand, desktop publishing, intelligent tutoring systems, and virtual reality" (Abstract). Since then, researchers have addressed the impact of virtual learning spaces on institutional and educational goals and organization (Epper \& Garn, 2004). Even when institutional goals, mission, are aligned with educational goals the virtual environment may not be may not meet the learning needs of all students. Creating the technology to support student learning, and determining how new technological experiences and events can inspire new ways of looking the curriculum content and structure (Duin et al., 2012). Technology, therefore, will inform the evidence of student learning outcomes as well as designed learning experiences.

The challenge in curricula design is reconciling diverse curricula goals in collaborative efforts across institutions with technology that informs student learning. When collaboration and cooperation undergirds the pedagogical effort (Van Dusen, 1997; Blackmore, Pettigrove, Johns-Boast, Compston, Thompson, Quinn, \& Lonie, 2012), university instructors do not need to know and do everything (Duin et al., 2012). They share research and pedagogical expertise. In a review of the conceptual basis for interprofessional collaboration, D'Amour, Ferrada-Videla, San Martin Rodriguez and Beaulieu (2005) found that collaboration was conceptualized and expressed in a wide variety of ways. They identified sharing, partnership, power, interdependency and process as concepts that inform cross-institutional inter-professional collaborations. Despite the prevalence of collaborative teaching, scholarly literature does not often address collaborations across higher educational institutions (Blackmore et al.) hence the need for this report. The reason for this gap in the literature might be the numerous models and understandings of collaboration in higher education. For example, Shephard (2004) describes effective collaborative relationships among libraries as shared articulated goals, equitable and well-defined roles 
and responsibilities, mutually beneficial and risky, accountable, shared resources and open in communication. Blackmore et al. provide five models of cross-institutional collaboration that feature jointly or separately developed and delivered forms of online and face-to-face teaching. Curricula development and delivery practices inform the nature of the collaboration. Hope and Peterson (2002) view collaboration as on a continuum from sharing resources and activities at one end to sharing common goals differentiate among networking, coordination and collaboration. They argue that as commitment to common goals become stronger, so does mutual benefits and relationships among participants become more formal (Hope \& Peterson, p. 23). Also, when content and skills needed vary; complex and contested interdisciplinary and inter-educational level curricular designs emerge from cross-institutional collaborations, much like cross-institutional research collaborations. Cross-institutional learning class designs accentuate the need for virtual learning spaces. Virtual learning spaces support expanded access, increased communication and collaboration with and among students (Epper \& Garn, 2004), thereby increasing networks and spreading costs (Gibbons, 1998). Even though virtual learning spaces may not meet the needs of all students, small groups within and across institutions, they demand much more learner initiative. In this paper, the learner is at the center of the collaboration. Within and cross-institutional collaborations, included coordinating shared resources and learning activities (Hope \& Peterson, 2002) and courses were separately developed and delivered in face-to-face interactions with some sharing (Blackmore et al.) with defined roles and responsibilities (Shephard). How curricula designs inform cross-institutional course goals, the delivery of instruction and learning dispositions for learner autonomy with collaborative intent needs deliberate attention.

\subsection{Interdisciplinary, Inter-Educational Levels \& Cross-Institutional Instruction}

Curricular relevance in higher education for the public good has always been at the forefront of educational goals. Service orientation in collaboration and communication, transfer knowledge to other areas while solving problems creatively, and contributing meaningfully with imagination, responsiveness and innovation to society are the expected qualities of a higher education graduate (Gibbons, 1998). Creating relevant curriculum in higher education for nurturing graduates with the qualities Gibbons lists, demands careful design and must be theoretical and evidence based (Åkerlind, McKenzie, \& Lupton, 2014). The interprofessional expertise of the collaborators, one whose primary research area is children's play and the other geospatial systems substantiated the theoretical and evidence basis of the courses' design.

The study of play as a college offering is common in early childhood (Roopnarine \& Johnson, 2001; Marfo \& Biersteker, 2011), physical education, and psychology programs. Because play is fundamental to living (Huizinga, 1938/1955), and culture (Roopnarine, Johnson, \& Hooper, 1994; Addo, 1995; Dzansi, 2004; Roopnarine, 2010) and forms of play inform how people make sense of their lives, it is a cultural practice. Culture is experience, thought and ways of beings, embodied in interactions. The different forms of play interactions include: sensorimotor play, unoccupied play, solitary play, onlooker play, parallel play, practice play, associative play cooperative play (Parten, 1932), competitive play, symbolic or dramatic play, imaginary play, collaborative play, constructive play and games. Naturally objects of play, such as toys and games, differ across culture (Sutton-Smith, 1986) and over time (Nwokah, 2009). Play culture is also discussed extensively in anthropology (Opie \& Opie, 1969; Schwartzman, 1978; Lancy, 2002), and education (Pellegrini, 2009; Jarrett \& Burnley, 2010; Holmes, Linden, \& Shin, 2013). Schwartzman viewed play as transformation of self in a culture and for Berlyne (1969), during play one attains varying levels of excitement. Czikzsentmihalyi (1981) illuminates the thrills and enjoyment that comes with play, as well as paradoxes in the definition of play, describing it as "flow" when "one practices behavior without dreading its consequence". Jarrett and Burnley make a distinction between "play", as diversion and engagement in freely chosen, enjoyable, and non-literal activity, stimulating creativity and "playfulness," as a subjective disposition or situation where one feels playful and uninhibited. Playful dispositions link cultural values and thinking styles, and engaging in play increases academic achievement of children (Holmes, Linden, \& Shin). In music education (Addo, 2013; Campbell \& Wiggins, 2013; Harrop-Allin, 2010; Mans, 2002; Marsh, 2008) and ethnomusicology (Mink, 2002) play scholarship focuses on the analysis, its sound, text, movement organizational features as well as pedagogical value. Play is not only fundamental to humans but also to animals (Pelligrini \& Smith, 2005; Burghart, 2010) Burghardt's (2010) criteria for recognizing play in nonhumans includes spontaneous, not fully functional, and repeated behaviors initiated when the animals are well fed, relaxed or in competition with one another. Several scholars place value on the role of the mind in play and vice versa (Holmes, Linden, \& Shin, 2013; Piaget, 1954; Erickson, 1956; Vygotsky, 1967). In Piaget's view play demonstrates the cognitive function- "assimilation". If play is a mental activity (Vygotsky, 1967) then, it makes visible what people are thinking (Erickson, 1956). Hence, play supports self-regulation, problems solving, creative and a number of other thinking skills. Addo 
(1995) has explained elsewhere how children make sense of the world around them while playing singing games, arguing that children create culture and are cultural interlocutors during play. The complexity attending the definition of play lead to Sutton-Smith's (1997) treatise on the ambiguity of play, discussing seven rhetoric's of play: progress, fate, power, identity, self and imaginary, and frivolity. Eberle (2014, p. 231) views play as "unfolding as a series of events driven by emotional experiences". In this paper, play as a phenomenon embraces all expressions of play described and includes all the forms, objects and places of and spaces for play.

Elsewhere, Addo (1995) has argued that the time-space and visual elements of play are best captured, presented and analyzed with multimedia. Therefore, when developing a course on play, the context of play and how best to capture plays interdisciplinary nature in time-and space needs to be taken into consideration. Digital narratives, "short (three-five minutes) movies featuring images, video clips, sounds tracks with narration" (McLellan, 2007, p. 66) move beyond presentation and analysis to facilitate learning and encourage learners to engage critically with cultural texts (Clarke \& Thomas, 2013) and what they communicate. Since play is cultural text, it is logical for the course developers to consider digital narratives as a way for conveying, communicating and preserving stories about varying forms, places and expressions of play. There is an increasing record of the value of digital narratives in education (Benmayor, 2008; Robin, 2008; Lea \& Jones, 2011; Yang \& Wu, 2012). These include increasing students' understanding of course contents, curiosity and critical thinking (Yang \& Wu), how theory emerges from personal understandings of identity and places of belonging (Benmayor) to supporting student engagement through motivation if organized using Mishra and Koehler's (2006). Technological Pedagogical Content Knowledge (TPCK) framework (Robin). Lea and Jones (2011) outline several ways in which students engage digital literacies for multimodal learning, arguing that "spheres of meaning making' is located at the intersect of participants (people and technologies) modes (written verbal and multimodal texts) and practices (particular institutional and social contexts) (p. 384). They found that students rely on the authority of the institutions for accessing and utilizing web-based resources for assignments and recommend that more attention needs to be placed to textual practice on learning, and less on the technologies and their applications. Perhaps Lea \& Jones' sense making occurs at Robin's thoughtful interweaving of key sources of knowledge, namely technological pedagogical content. Our project engaged this balance by using within and cross-institutional collaborations capitalizing on our within institution resource partners as well as our distinct and interprofesionnal expertise.

Play culture mapping provides information the uses and availability of outdoor and indoor spaces. Additionally, the quality of play spaces, resources available on play spaces, locating play deserts in communities as well as trends in the provision of play spaces can be captured in maps. Adapting Crawhall's (2007) definition of cultural mapping, play culture mapping involves the representation of play landscapes in two or three dimensions from the perspectives of local people and supports the need for geospatial mapping. Using geographic information systems (GIS) maps to capture rich contextual playspace information with historical, intercultural material. The demand for geospatial skills is growing and expanding to areas beyond geography (Gerwin, 2004; Sinton 2009), crime mapping in public affairs (Ferrandino, 2014) to business. Gerwin (2004) highlights higher education institutions' role in preparing students with information geodemographics, spatial data infrastructure, and spatial analysis. The approaches universities can take to present this knowledge in single courses or a series of workshops (Feranndino) or problem-based learning, service learning and civic engagement activities (Sinton). Karsten's (2002) study of Amsterdam's spatial transformation from the point of view of children, examines children's outdoors spaces, leisure centers and care institutions. Karsten does not interview children to find out their perceptions of these spaces but rather observes what is available for children. Maps Karsten created, highlighted the marginal role children played in the planning and design of residential areas. How this landscape has changed over the years with a change in cultural demographics was also not mapped, and there were no digital narratives about the play. Further, when combined with digital narratives the navigational potential (McCurley, 2001; Rouse, Bergeron, \& Harris, 2007) of spatial web browsing of geospatial map supports knowledge discovery and information retrieval from locations in context while browsing the web. The geospatial web has from its inception supported participatory GIS projects, because it incorporates local knowledge to "promote public access and collaborative mapping" (Rouse, Bergeron, \& Harris, 2007). Collaborative learning in participatory GIS projects makes it viable context for learning as well as research. Hence, Baker et al. (2014) have developed a research agenda to support empirical investigations on the study of geospatial technologies and learning. Bell (2013) organized an undergraduate seminar on play highlighting experiential learning through cooperation, interactions, awareness of the diversity of play and responsibility in well-being and game interactions. Referring to Chickering and Gamson's (1987) seven principles for undergraduate education, Bell argues that the study of play in the general curriculum is logical. However, Bell's students did not map play culture. Thus, our project departs from Bell's (2013) undergraduate seminar on play, in that our approach to 
student learning experiences in curriculum design was both phenomenological and discursive. How students construct their understanding of play experiences in cultural contexts through digital stories displayed in maps allow for the study of cross-cultural, multi-level and interdisciplinary curriculum design. Play culture mapping is a platform for intercultural interactions and dialogues (Crawhall) within on campus classes and among locals in play contexts.

\subsection{Intercultural Competencies and Interdisciplinary Learning in Cross-Institutional Instruction}

Educating culturally competent students through the global experiences within local communities is gaining attention in higher education curricula research. Gaining (cross)-cultural competence centers on 'individuals propensity for more proactive, creative and reflexive use of cultural knowledge in competent cross-cultural behaviors.'(Chiu, Lonner, Matsumoto, \& Ward, 2013). Looking closely at cultural studies in the academy, Goldberg and Greenberg (2004) demonstrate the importance of cultural analysis of embodied intercultural interactions, because it enables learners to reframe perspectives acknowledging the impact of socio, cultural, and political systems of organizational success. The study of the organization, place and space of play within the academy warrants such analysis because this will empower students to frame their agency and legitimize their knowledge (Goldberg \& Greenberg, 2004).

Within intercultural contexts these interactions provide opportunities for cultural clusters of people to negotiate their play. Veitch, Salmon and Ball (2008) conducted a study of Australian children's access to free play spaces in their neighborhoods, and how these vary by age, sex, and socioeconomic status. They found that children in lower SES had to travel further than other children to access local parks. They recommended support from local governments, urban planners, and community groups to include access to parks and promote a sense of safety within these parks. Richness of intercultural play patterns reflect people's views and values and are constrained or promoted by resources in the locale. The goal of intercultural competence begins with the awareness of variation in-group cultural patterns. Awareness is not possible with a deliberate consciousness and interaction with local. Hence curricula designs that promote intercultural competence through cross-disciplinary work in intercultural contexts, may facilitate viewing cultural patterns as possible and probable rather than fixed (Moore $\&$ Woodrow, 1999). Their wheel of culture map provides a multidimensional picture of play culture, and assumes that interaction through intercultural dialogues about play and how to represent play provides a diversity advantage (Moore and Woodrow).

The interdisciplinary curriculum is, by its nature, relevant because, it demands explaining why and how disciplinary concepts in curricula are integrated for maximum student learning (Jacobs, 1989). There is ample research on the impact of interdisciplinary curricular designs in higher education on student learning. Jacobs and Frickel (2009) conducted a comprehensive review of interdisciplinary efforts in higher education, taking a cross-sectional view of connections between disciplines in communication, knowledge diffusion, research, assessment, and at research centers. They argue that there is not enough evidence to make a case for interdisciplinary learning over disciplinary in higher education. Perhaps, considering interdisciplinary from the standpoint of curricular design for significant student learning might be the answer. Curricular designers provide different types of learning environments, and the construction of learning environments around for example, group work, problem based learning, team based, and project work for interdisciplinary learning. Interdisciplinary learning allows the student to celebrate and harness previous experience in learning rather than a banking approach (Freire, 1985). Interdisciplinary curricula design makes generative and transformative teaching models possible (Wink, 2010). In generative teaching models the teachers and students are close together asking questions, speculating, and dialoguing during learning. While, Jacobs and Frickel (2009) might beg to differ, transformative teaching and learning models can emerge in interdisciplinary contexts because they allow students to go outside their comfort zones. Wink argues the transformative models extend the classroom into the community and encourage the integration of knowledge (Fink) in a variety of learning environments. Interdisciplinary learning allows the student to celebrate and harness previous experience in learning thereby increasing learner autonomy (Freire, 1985). Networking changes classroom roles to support hybrid, blended and flipped instruction in higher education (Crews \& Butterfield, 2014) and learner autonomy. Additionally, Wyatt and Bloemker (2013) demonstrate how learners autonomy contributes to intellectual development for the first year experience. They identified "self-management, relationship, and tolerance skills; and behavioral and perceptual flexibility" as key components of the social and emotional competence of university first year students.

There is ample research demonstrating the link between the first year experiences and students success beyond the university (Van Dusen, 1997). Thus, the design and delivery of instruction from the beginning and how these intersect with other areas and levels of education, the motivation of this paper, is important. When designing 
interdisciplinary instruction using a variety of teaching strategies and activities, learning environments, and organizational and management techniques is inevitable. For example, elective classes within first year experiences are opportunities for instructors to the break mold of adhering to traditional disciplines and creating new classes that encourage interdisciplinary and multisite innovations. Curricula designs that encourages first year experiences to intersect with classes at higher levels, reflects Noddings' (2013) "promising alternative" to traditional discipline centered offerings, because it allows students to consider the intellectual advantage of working with interdisciplinary materials at different levels of competency. The interdisciplinary nature and cross cultural dimension is similar to ours, yet, our project departs from Bell's (2013) undergraduate seminar on play, in that we connect across courses with cohorts of students at different level of their education.

Freshman seminars enrich the first year experience of new students in small classes, and give faculty the opportunity to create courses that are exciting and engaging. Therefore, in a University of Minnesota Twin Cities (UMTC) Freshman seminar titled: Mapping Arts Play in the Twin Cities, students observe children from diverse ethnic and socioeconomic backgrounds play in child initiated and created play spaces. Focusing on out-of-school communities of the Twin Cities, the students selected the Cedar-Riverside neighborhood to tell engaging stories about play. They conducted and analyzed observation, interview, visual and archival data to capture the essence of the play in their digital stories. Then, University of Minnesota Crookston (UMC) students in the Geographic Information Systems Applications (GIS), reviewed digital stories created and noted the intent of the UMTC student authors. UMC students then reflected on the various aspect of the story that were spatial in nature that could be integrated into an ArcGIS Online Story Map template. Spatial elements that seemed more relevant to the GIS student were then incorporated into the digital story through the creation of Story Maps. Examples of the final Story Maps can be accessed here: https://sites.google.com/a/crk.umn.edu/mapping-arts-play.

The purpose of this article is to discuss a collaborative effort of two classes on different campuses to map play in the culturally diverse Cedar-Riverside neighborhood of the Twin Cities. Working collaboratively across campuses, participants examined closely personal play histories and its impact on learning as well as the meanings people ascribe to the places they play. Two questions inform this effort: What was the evidence of significant learning among students? How did the collaboration impact the teaching and learning process? The findings of this case study will inform the design of future interdisciplinary and cross-institutional learning. In what follows, we will discuss the framing of the classes with Dee Fink's, our approach to answering our first curriculum design question and our reflections on the observations we made about our second question.

\section{Method}

\subsection{Framing the Classes}

Dee Fink's $(2003,2013)$ Taxonomy of Significant Learning framed the development of both classes. This taxonomy encourages a close consideration six dimensions of curricula design-disciplinary foundational knowledge, the application of knowledge in new contexts, integration of knowledge from a variety of placements, considering the human dimension, caring, and learning how to learn. The table below shows how, for both the UMTC and UMC classes, the six dimensions of the taxonomy encourages active and engaged learning such as problem solving, case studies, role playing, and online learning.

Table 1. Fink's (2003) taxonomy of significant learning and the course

\begin{tabular}{|c|c|}
\hline$U M T C$ & $U M C$ \\
\hline $\begin{array}{l}\text { Foundational Knowledge: } \\
\text { - Play different forms of play from } \\
\text { cultures in today's world. } \\
\text { - Integrate diverse perspectives and } \\
\text { dispositions while planning and doing play. } \\
\text { - Compare and contrast diverse forms of } \\
\text { play through social, intellectual and physical } \\
\text { interaction. } \\
\text { - Articulate impediments to and } \\
\text { enablers for play on campus, at home and in } \\
\text { places you deem viable. }\end{array}$ & $\begin{array}{l}\text { Foundational Knowledge } \\
\text { - Gain functional use of various GIS and } \\
\text { online mapping resources. } \\
\text { - Understand spatial aspect of culture. }\end{array}$ \\
\hline
\end{tabular}




\section{Application:}

- Use feedback from peers and community that encourages interactive engagement for hands-on play learning, critique, analysis and learning transfer.

- Through experiential learning, this course will prepare students to develop real and reciprocal relationships with children and community organization that support and promote arts play and other forms of play.

Integration:
- Use field research experiences to
describe, and recognize the roles of
creativity, innovation, discovery and
expression in a variety of arts play styles and
forms.

\section{Application:}

- Use GIS Desktop, ArcGIS Online, and ArcGIS Story Map Templates and other technology to communicate various aspects of play and culture.

- Create a map that communicates various aspects of play.

\section{Integration:}

- Connect similarities and differences in ones own culture with those of others.

\section{Human Dimension:}

- Bring critical and adaptive perspectives to the discussion of play while paying attention to students' personal, family, and community experiences and cultural norms.

Caring Goals:

- Explore how available arts play spaces can inform decisions, and opportunities for encouraging spaces for arts play.

- Create playful environments that are grounded in the cultural and learning experiences of each other.

\section{Learning-How-to-Learn Goals:}

- $\quad$ Using digital visual media tell stories about play in the Twin Cities.

- Use Mapping Software to identify, and map digital stories about play in the Twin Cities.
- $\quad$ Bring critical and adaptive perspectives to the discussion of play while paying attention to students' personal, family, and community experiences and cultural norms.

\section{Caring Goals:}

- Explore how available arts play spaces can inform decisions, and opportunities for encouraging spaces for arts play.

- Create playful environments that are grounded in the cultural and learning experiences of each other.
- Find and utilize "help" resources that show how to work around technical problems and to learn new software.

\subsection{Description of Participants and or Context}

Eleven UMTC freshmen and women and eight upper level UMC undergraduates participated in the project. Course success pivoted around three elements: (1) coordination between the two classes, (2) the acquisition and application of technical knowledge by students and (3) student collection and interpretation of data about play within the study area. The students used the following sequence to complete the assignment: researching the study of play, student data collection (site visits, photos, interviews), digital story creation, and story map integration.

\subsection{Coordination between Classes}

Three hundred one-way driving miles separated the two campuses; therefore, face-to-face meetings between the students were not practical. Course instructors visited in-person once during the course and maintained regular contact via email and video conferencing. When the digital stories were completed by UMTC students and were ready to be given to UMC students, several video conference calls between these students were held to enable 
transfer of the project and contribute to the continuity of intent. A final viewing of the mapped digital stories was video recorded and shared with both classrooms.

\subsection{The Acquisition and Application of Technical Knowledge}

Students needed specialized knowledge (ArcGIS Online and designing digital stories) to make mapping the digital stories possible.

ArcGIS Online, by Environmental Systems Research Institute (ESRI) greatly increases the access and transferability of digital mapping by providing an online platform for creating, editing and communicating spatial information. When compared to other digital mapping software, the platform is relatively simple to use, at the same time it is somewhat limited in the process and functions available. When more complicated geospatial processes are needed it combines well with other GIS software programs, particularly the ArcGIS Desktop Suite. Prior to the class UMC students have introductory exposure to ArcGIS Desktop programs, and needed to apply previous knowledge and learn new techniques to map play in the Cedar-Riverside neighborhood. Instructor led exercises and supervision as well as online tutorials helped students become competent with the online platform. Once the data was in the ArcGIS Online program, students then applied the ArcGIS Online Story Map Templates to create final story based web pages.

Digital story teams on UMTC campus determined the context for study, observed how people from diverse cultures shaped play and interviewed people from the selected context to hear the stories they told about play. Student teams captured their observations and interviews in text, audio, visual images and music. Analytical reflections on observations and interviews provided information for developing storyboards with selected and edited audio, digital photography and videography. Guests from the university library system shared information on resources available for the digital story telling process. In addition to information on what is available in the library for research on arts play, librarians shared information on Google maps, Google fusion tables, archival resources on the contexts, where to reserve recording equipment, video production support and backup, and copyright.

\subsection{Collection and Interpretation of Data within the Study Area}

As faculty and students observed the dynamic nature of play in cultural contexts, they engaged in critical conversations about play spaces and how culture impacts the stories people tell about play. Also, students participated in play and community events and reflected on and synthesized key issues that emerged in the digital stories created. In class, students discussed connections between different play patterns in the U.S. and diverse cultures of the Twin Cities. Because of the experiential nature of the class, students conducted observations and interviews with community members and public servants, shared play from their childhood and learned how to ask questions about access, equity and quality in response to the realities of play. In the three-day a week one-hour class, UMTC students spent the first two days (Monday, Wednesday) in class, and the Friday in the field (See Appendix A for the week-by-week schedule.) We began the digital story project "looking for" the parks with play spaces in the Cedar-Riverside neighborhood. After each field observation students responded to a reflective prompt on the course management website. Following our preliminary observations, students paired up and decided on topics for focused participant observations. In class activities, readings, assignments and discussion board reflections encouraged students to reflect on the implications of play for the international community, the US and in their lives. UMTC students adapted Rubin's (2001) Play Observation Scale (POS) for use in the field and completed basic training on ethical practices in field research projects with the university's institutional review board.

The culmination of these efforts resulted in the production of digital stories regarding various aspects of play. The title of digital stories indicates the range of perspectives the students gained while engaged in the course. Some of these include: Culture and Children's Play in Curry Park; Comparison of Riverside Park: 1919 and Now; Evolution of Play in Curry Park; and Who Let the Dogs Out at Riverside Park?

All student participants signed releases for instructors to present their projects at conferences post to U-Spatial or Digital Story website at the University.

\subsection{Assessment}

Assessing student learning on mapped digital stories occurred at various levels. Direct observation and consultation with instructors and peers allowed immediate feedback and direction. Instructors assessed transcribed observations of play contexts, and interviews and analytical reflections on observations, interviews, related readings, as well as, culminating projects. 


\subsubsection{Digital Stories}

Gorski's (2000) work in evaluating educational websites questions from a colleague, Catherine Solheim's digital story grading rubric for her class on Global and Diverse Families informed the assessment of final digital stories. See Appendix A for the details on digital stories evaluation. Indexes of evaluation included relevance and appropriateness of context, clarity of story purpose, understanding of play context and content, quality of product, credibility, accessibility, economy and succinctness, navigability and intercultural perspectives on children's play.

\subsubsection{Student Reflection Survey}

To gain a student perspective on learning a survey was given to the students after the assignment. This survey was created by Norris (2012) and adapted for use for this assignment. Once collected analyzed responses to questions that had a rating of 4 or higher (on a 1-5 scale) were noted as significant. Assessment of student learning also occurred through instructor descriptive and content analysis of this survey given to the students and the examination of the digital story map assignments. Finally, in response to the first question, What was the evidence of significant learning among students?; the survey results and direct instructor assessment of the assignment were then reflected back onto the Fink (2003) taxonomy for further understanding of student learning.

\subsubsection{Faculty and Student Reflection on Implementation Process}

The results of a content analysis of open-ended questions the student reflection survey as well as instructor reflection on the implementation process determined impact of the collaboration impacted the teaching and learning.

\section{Results}

\subsection{What Was the Evidence of Significant Learning among Students?}

To assess student learning on the project students completed a paper survey created for the digital story assessment (Norris, 2012). The survey questions consisted of dichotomous, multiple choice, Likert Response Scale, and open ended questions. Survey questions were categorized into Fink's (2003) taxonomy to better understand learning as evidenced through survey responses. Survey responses that were a mean of 4 or higher on a 5 point Likert Response Scale were deemed significant and will be discussed further. Additional significance was gleaned from the other survey questions and the final student assignments themselves.

\subsubsection{Learning How to Learn}

Self-selection of student topics required self-directed learning, as students, not the instructors became the experts on their topics. The role of the instructors was to guide efforts and provide access to technical resources. As a result students "learn(ed) a new skill/way to use technology to effectively communicate ideas to others". Student also learned the importance of feedback in the acquisition of knowledge, specifically from instructors and peers. Course design parameters also helped students learn the importance of project management. Students worked in groups in their respective courses and across campuses. This group work across campuses elicited responses like "(I would) get started on the project earlier" and a desire for earlier coordination across campuses. Students also remarked on the importance of compromise when working on group projects.

\subsubsection{Integration}

Through gaining new technological ways of communicating allowed students to "improved my ability to articulate and share my own story with others". Students were very intentional in selecting images and music that helped them convey their messages. They integrated field research experiences to describe and recognize the roles of creativity, innovation, discovery and expression.

\subsubsection{Human Dimensions}

As evidenced in the topics and content of the digital stories themselves, parameters of the project demanded that students pay attention to personal, family and community experiences and cultural norms about play. Historical content of stories included observing changing demographics from Scandinavian to East African, Swedish, Slovac and Jewish to Somalia showed it was impoverished then and now. They considered the history of Riverside park and the Coyle Community Center and how the role of the Center has changed through time to meet community needs. They raised questions about the quality of play spaces in the park, and changing forms of entertainment. Students observed variations in amount of play depending on the seasons and time of day, and the variety of activities offered by the center and how that affected their data collection and impacted learning. They noted the increasing amount of types of play activities being programmed. They raised questions about the 
accessibility of the park - supervision - and collected crime data on how this affected accessibility to parks. Additionally, as mentioned previously, group project dynamics and compromise were also used for significant learning.

\subsubsection{Foundational Knowledge}

The assignment also elicited students to compare and contrast diverse forms of, dispositions about and perspectives on play. Cultural reflection on the variety of aspects of play that students observed facilitated student reflection on enablers and impediments to play on campus, at home and in the community. The evidence for foundational knowledge in cultural expressions emerged in the analysis of their digital stories. Students observed acknowledged the diversity of the area and differences across generations in stories. They understood the shifting cultural patterns of play from physical to virtual interaction and became aware of the impact of privilege on access to virtual forms of play in Somalia and the U.S.A. They also raised questions about safety in play spaces across cultures.

\subsubsection{Application}

Strategic application of newly acquired technological skills allowed students to tell the stories of play. One surprising note from the GIS class was the number of student who indicated that they would share their work on this project with potential employers as an example of their creativity, even though the subject of the projects was outside their respective career fields. The level of student investment in the project was also noteworthy as students used feedback from peers and local community members for stories about play, critique and analysis. Students remarked on the level of creativity employed when selecting images and music that contributed to the stories being told. Regarding images and music, project parameters required students to demonstrate academic integrity in the selection, use and citation of images and music. Survey responses indicated that students intentionally applied these principles in their projects.

\subsubsection{Caring}

Learning that occurred during image and music selection also indicate a level of sensitivity towards the work of others that were used in the student projects. A significant number of the students indicated "I tried to be thoughtful and considerate of other people's work when gathering images and music". For some students the care they took to explore how available playspaces can inform decisions, and opportunities for play is evident in the stories they told and indicate a deeper level of concern for these issues.

\subsection{How did the Collaboration Impact Teaching and Learning?}

Throughout the semester, teaching and learning strategies, content and focus had to change to meeting the needs of the collaboration. The realities of our field's physical space, weather conditions, ethical and intercultural considerations, frequency of dialogues among classes and pacing determined the changes.

\subsubsection{Weaving Ethnographic Fieldwork with Technical Knowledge Acquisition}

The teaching and learning challenge was to give the students both the technical knowledge for collecting data in the field and also the ethnographic techniques to create rich digital stories. Several students already had the technical skills to capture observations and interviews in text, visual and audio format. One student had previous experience with putting together short films and therefore felt very comfortable working in the field with a camera. UMTC Instructor's intention was for the students to engage in an iterative process using, their story focus and the data they collect to create a digital story. It was interesting to observe how some students used the images to as the primary basis for the digital story. That digital story unfolded faster than the digital stories that were developed from focused storyboards, with a balance of substantiating interview data, observation data and narrative. Research effort determined the depth of the narrative and the richness of the story. Most devoted at least 4 hours to thinking about their digital story, gathering materials, creating and producing a digital story. Although most acknowledged the challenges of digital story creation, they were quite pleased with the product. Here are some comments:

\section{"Digital stories allow the student to tell the story in a creative and more powerful way." \\ "Yes, (I would share my digital story with others (family, colleagues, friends, etc.), because I think my story is creative and interesting, and it conveys a message I think other would want to hear."}

Also, ethnographic fieldwork needed to consider also the spatial elements story. One UMC students commented: "In the mapping aspect it was sometimes hard to convey the stories true meaning. Some stories didn't have allot of spatial elements." Thus, the information some of the UMC students needed to develop spatial elements in the maps were not captured by UMTC students. 


\subsubsection{Shifts in Content and Context Focus}

The realities of our field's physical space, weather conditions, ethical considerations determined shifts from studying about singing games and clapping games to studying play. Weather conditions of the fall semester in the Midwest demanded that we completed our field exploration early before the snow fell and shift content and context focus. First, even though, an interviewee told students that children filled the parks in the summer, there were no children in the fall to observe. After school programs at Brian Coyle Community Center built next to Currie Park attracted children the Cedar side of the community. We had to extend the spaces for play beyond to playground to the community center on the playground.

Second, with a limited number children playing outside, mainly organized sports, UMTC student could not observe arts play, such as singing games and clapping games. In the community center, free play and basketball in the gymnasium. The realities of our field's physical space determined the content of and context of the project. Thus, like Karsten (2002), UMTC students observed spaces available for children to play rather than what they were playing.

Third, while planning the course, UMTC instructor was interested in children's after school arts play. However, the teaching and learning process had to change because students could not interview any children because the institutional review board's ethics requirements. Thus, the administrative hurdle led to a shift in context and context focus. Obtaining organizational approvals did not impact the cross institutional collaboration because of our collaborative model: separate course development with consultations and separate delivery with sharing resources and activities.

\subsubsection{Intercultural Considerations}

In class activities and discussions were designed to helps students to become aware of and be interested in developing personal intercultural competencies. Sanderson (2009) calls for international faculty to know who they are particularly when working in intercultural contexts. There are several exercises for developing intercultural competence. UMTC students wrote an autobiography, connecting their experiences as learners to their strengths (Note 1), and play experiences. We discussed the need for being self-awareness and cognizant of personal values, cultural and ambitions, the knowledge of various cultures and the need for skills to apply knowledge and awareness to engage a culturally appropriate behavior within cultural groups. Also, considering forms of intercultural play communication, students developed intercultural communication skills for interviews.

\subsubsection{Motivation, Pacing, Teamwork and Learner Autonomy}

The extent to which students can stretch their imagination working together in collaboration across campuses informs the value of inter-institutional classes. Students responses to sharing collaborative work beyond their immediate families and friends reveals the value they place on the effort. One UMTC student responded to the question "Would you share your digital story with a potential employer?" with "No, because I'd want to show something that is my individual work and probably higher quality." Others found the experience useful for demonstrating their research and technology skills and creativity. Here are some comments:

\footnotetext{
"Yes, most likely, because it shows my ability to get creative and passionate."

"Yes, if anything, it would show the skills involved in gathering information and presenting it."

"Yes, because it demonstrates my skills and abilities when working with technology and other people."
}

A UMC student who would have loved to create a digital story related to Natural Resources and mapped it, appreciates the experience. "I wish I could have created a NatR related digital story. Something I would be able to use or to get an idea from. I do like that I at least know about this process now. "For this student the collaboration created ideas for another potential project. From the instructor standpoint, it was a challenge to observe consistent motivation and effort in some groups. It was also disappointing to see a strong student come up short on preparing the digital story in time for mapping because of an inability to work with the other student. Perhaps facilitating several dialogues among the students from the two campuses may increase connectedness and ownership of the final projects by all students. UMTC students tasked with creating the digital stories initially felt overwhelmed by all the tasks and skills necessary to complete the project. When the mapping of spatial components of their stories was introduced they were greatly relieved to learn that other students with more mapping experience were going to handle this part of the project. The collaboration allowed more depth to the learning experience and more a complex and rich final product.

\section{Discussion}

The study and mapping of play behavior demanded that students consider cultural beliefs about play, purpose of 
play and practices, for developing digital stories. Students described awareness of their personal beliefs about play, reflect on their learning in discussions and writings. Roopnarine (2010) argues for the need for students that address "socialization beliefs, goals, and practices and cultural pathways" (p.21) that frame children's play in diverse cultures. Roopnarine calls for studies on acculturation status and changes in ethnotheories about play, the culture-specific work play relationship and broadening the definition of play to include a wide range of playful activities. In what follows we will discuss the ethical dimensions of non-fiction narratives in digital stories, project relevance and its relationship to learner autonomy and ownership, the importance of multimodal literacy in the academy, and provide implications for future practice.

\subsection{Ethical Dimensions of Non-Fiction Narratives}

The nature of the neighborhood, an immigrant neighborhood, demands that students also consider acculturation and ethnic theories about play (Roopnarine, 2010). A study of the phenomenon of play in context demands consideration of personal perspectives and knowledge about play. These perceptions may stem from the view of play context as in constant flux (Schippers, 2009) because people interact with original and new habitus. In order to create accurate narrative about play contexts, students had to understand their play selves, play acculturation and recognize the experience as play. Burghardt (2010) identified five criteria for recognizing play as only fully functional in a context, spontaneous and intentionally pleasurable, incomplete, repeatedly performed, play animal must have basic needs met and be under no stress (pp. 13-16). Even though Burghardt's couched his classifications from the non-human play, the classifications extend the breadth and narrative possibilities of play. If the context is in constant flux, because of the people and animals who engage in play move in and out of the play contexts then, the validity of digital narratives depends on the recognition of flux in context, people and animals. Cross-institutional reflections on narratives and representations in map demonstrated how students critically examined the processes and contexts that framed play in the Cedar-Riverside neighborhood. Ethnographic study that links surrounding community to academic learning demanded considering personal biases, recognition demographic shifts in contexts, rendering a respectful treatment of narratives. Respectful in that students learned to acknowledge the voices of informants, importance of seeking permission for digitized information and the careful design of narratives and maps to fully capture the shifting stories in Cedar Riverside.

\subsection{Project Relevance, Learning to Learn and Ownership}

While digital stories may be the most recent "trend" in higher education, they need to be relevant to the curriculum as well as in the students' lives. Significant learning occurs when curricular designers construct learning environments that give students autonomy and ownership in their interpretation of learning experiences as well as provide opportunities for the sequencing and representation of learning in innovative avenues. However, student perception of the relevance of the collaboration may vary, hence Blackmore et al. (2012) propose that course developers manage the change in the management process of projects from the onset. Students in both classes needed to grasp disciplinary concepts in play and mapping (Åkerlind et al., 2014) before bringing together, re-sequencing and re-presenting their understanding of play in culture, time in interactive multidimensional mapping environments. Instructional activities supported learning how to learn and ownership and include modeling for the learner, coaching and scaffolding learning (Jonassen, 2012). Variation in understandings will occur because of the team approach and multilevel classes (Åkerlind et al., 2014). The learner is empowered to conduct research, integrated theory and practice on mapping play, apply their threshold concepts and skills to develop a viable solution to the problem -mapping play that captures intercultural variation, and historical changes in context. Learners pay attention to the audience; content selected and how they use mapping and digital story media, while they think through, question and find ethical ways to represent projects. Actively engaged in learning, they encounter problems for which instructors use as teachable moments for modeling, coaching and scaffolding learning (Jonassen, 2012) for significant learning (Fink, 2013) (See Relevance and Appropriateness evaluation questions in appendix)

\subsection{Multimodal Literacy and the Academy}

Current trends in education call for learners to be conversant in multiple literacies beyond traditional reading and writing. The New Media Consortium's 2013 report highlighted key trends, as well as new media technologies, to consider in multimodal literacy (Johnson et al., 2013). Connecting the amount of time students already spend with digital technologies and on the internet, the academy will engage students where they are for optimal learning. There are several ways students in higher education, like those in this project, engage digital literacies for multimodal learning; from word processing to library internet searches and downloads, designing multimedia presentations. Ntelioglou, Fannin, Montanera and Cummins (2014) argue that multimodality helps students to optimize learning and literacy (p. 4). The quality of multimodal education in higher education rests in its impact 
beyond the university (Van Dusen, 1997), curricula assessment strategies (Gorski, 2000), and evidence of significant learning (Fink, 2013). When interdisciplinary practices begin in the first year of higher education, students are more likely to succeed after they have graduated (Van Dusen, 1997). We would argue that interdisciplinary practices that transcend educational levels will predictably facilitate success in the real work. Additionally, the importance of Gorski's (2000) work on evaluating educational websites from a multicultural perspective gives credence to intercultural learning. Gorski argues for evaluating education media from the standpoint of its context. In the evaluation of final projects, learner understanding of foundational disciplinary concepts are "gateways" (Åkerlind et al., 2014) to making sense of disciplinary ways of knowing and we would argue increase multimodal literacy. Learners become aware of the wide range of resources available to them in the academy when they engage in multimodal learning. Also the appropriation of multimodal literacies in web-based technologies, digital technologies as well as traditional reading and writing demands grappling with responsible and ethical use of data.

\subsection{Implication for Future Practice}

The collaboration equipped our students to developed stronger digital skills, network with each other and take advantage of the resources on two campuses. The collaboration also gave us the opportunity to engage in writing for publication using a shared digital space - google docs. There are some inevitable implications for revision, because this is the first iteration of the class. In cross-disciplinary, multimodal classes it is important to

- Review and refine the video conference setup for more clarity. The video conferences across campuses were sometimes marred by the set up of the laboratories.

- Coordinate class times to overlap at least once per weeks to facilitate dialogue among the classes. As stated earlier this will increase conceptual understanding and ownership of the project and perhaps increase students' motivation and efforts on the quality of the final product.

- Revisit the class schedule to give technical staff the opportunity to interact with students early in the semester. This might reduce insecurities with technical equipment and software and increase awareness of breadth of these facilities on campus.

- Allow more time for Story Map creation. Less is always more when it comes to providing reflection and reimagining time in learning. Planning more time for Story Map creation will be giving students autonomy to work on their own, across campuses which means we will need to reduce the number of face to face meetings from professors to students and encourage more side by side meetings with their peers across campuses.

\section{Conclusions}

The collaborative effort made the classes, multimodal-GIS, cross-institutional, and ethnographic, linking the community with academic learning. The motivation for our collaboration was disciplinary and research intensive. We focused on evidence of significant learning and the impact of the collaboration on teaching and learning. Despite the challenges raised students engaged in critical conversations about play spaces and how these impact stories about play. They acquired intercultural communication skills while they researched how patterns of cultural beliefs and behaviors inform play in a rich cultural community of the Twin Cities.

\section{Acknowledgements}

The project was supported with funds from the University of Minnesota's, Office of Undergraduate Studies, Freshman Seminar enhancement funds, and Global Programs and Strategy Alliance's 2013-2014 Internationalizing Teaching and Learning (ITL) Fellows Program. The support is gratefully acknowledged. Tim Maloney, Head Librarian, Music Library created a website for the class and provided a session on library resources for research on arts play. Justin Schell, Libraries Research \& Learning - Arts Humanities, Wilson Library provided information on Google maps, and Google Fusion Tables. Linnea Anderson, Social Welfare History Archives of Elmer Andersen Library, presented on archival resources available on the history of play. Scott Spicer, Media Outreach and Learning Spaces Librarian, Walter Library, provided details on digital storytelling resources at the University of Minnesota. Finally, we offer special thanks to student participants.

\section{References}

Addo, A. O. (1995). Ghanaian children's music cultures: A video ethnography of selected singing games (Unpublished Ph.D. Thesis, University of British Columbia, Canada).

Addo, A. O. (2013). What's in a Singing Game? Exploring Children's Oral Literature. In L. Asimeng-Boahene, \& M. Baffoe (Eds.), African traditional and Oral literature as Pedagogical Tools in Content Area 
Classrooms: Pre-K-12 (pp. 21-41). Information Age Publishing.

Åkerlind, G., McKenzie, J., \& Lupton, M. (2014). The potential of combining phenomenography, variation theory and threshold concepts to inform curriculum design in higher education. International Perspectives on Higher Education Research, 10, 227-247. http://dx.doi.org/10.1108/S1479-3628(2014)0000010017

Baker, T. R., Battersby, S., Bednarz, S. W., Bodzin, A. M., Kolvoord, B., Moore, S., ... \& Uttal, D. (2014). A Research Agenda for Geospatial Technologies and Learning. Journal of Geography, (ahead-of-print), 1-13. http://dx.doi.org/10.1080/00221341.2014.950684

Bell, M. (2013). “You're taking a seminar on what?” Play as an Undergraduate General elective. Presentation to the $39^{\text {th }}$ Annual Conference of The Association for the Study of Play (TASP) and $26^{\text {th }}$ Conference of The American Association for the Child's Right to Play (IPA/USA), University of Delaware, Newark, Delaware.

Benmayor, R. (2008). Digital storytelling as a signature pedagogy for the new humanities. Arts and Humanities in Higher Education, 7(2), 188-204. http://dx.doi.org/10.1177/1474022208088648

Blackmore, K. L., Pettigrove, M., Johns-Boast, L., Compston, P., Thompson, L., Quinn, D., \& Lonie, A. (2012). Tales from inside the blender-Five models of collaboration. In Teaching, Assessment and Learning for Engineering (TALE), 2012 IEEE International Conference on (pp. H3A-12). IEEE. http://dx.doi.org/10.1109/TALE.2012.6360343

Burghardt, G. M. (2011). Defining and recognizing play. In A. D. Pellegrini (Ed.), Handbook of the development of play. Oxford University Press.

Chickering, A. W., \& Gamson, Z. F. (1987). Seven principles for good practice in undergraduate education. American Association of Higher Education (AAHE) bulletin, 3, 7.

Clarke, R. G. H., \& Thomas, S. (2012). Digital Narrative and the Humanities: An Evaluation of the Use of Digital Storytelling in an Australian Undergraduate Literary Studies Program. Higher Education Studies, 2(3), 30-43. http://dx.doi.org/10.5539/hes.v2n3p30

Crawhall, N. (2007). The role of participatory cultural mapping in promoting intercultural dialogue "We are not hyenas". Reflection paper presented for the UNESCO Division of Cultural Policies and Intercultural Dialogue in 2007.

Crews, T., \& Butterfield, J. B. (2014). Data for Flipped Classroom Design: Using Student Feedback to Identify the Best Components from Online and Face-to-Face Classes. Higher Education Studies, 4(3), 38-47. http://dx.doi.org/10.5539/hes.v4n3p38

D’Amour, D., Ferrada-Videla, M., San Martin Rodriguez, L., \& Beaulieu, M. D. (2005). The conceptual basis for interprofessional collaboration: Core concepts and theoretical frameworks. Journal of interprofessional care, 19(S1), 116-131. http://dx.doi.org/10.1080/13561820500082529

Duin, A. H., Anklesaria, F., \& Nater, E. (2012). Cultivating Change in the Academy: 50+ Stories from the Digital Frontlines at the University of Minnesota in 2012. Open Source Ebook. University of Minnesota.

Eberle, S. G. (2014). The Elements of Play: Toward a Philosophy and a Definition of Play. American Journal of Play, 6(2). 215-233.

Epper, R. M., \& Garn, M. (2004). The virtual university in America: Lessons from research and experience. EDUCAUSE Centre for Applied Research (ECAR) Research Bulletin, 2, 1-15.

Ferrandino, J. (2014). Incorporating GIS as an interdisciplinary pedagogical tool throughout an MPA program. Journal of Public Affairs Education, 20(4), 529-544. Retrieved from http://www.naspaa.org/JPAEMessenger/Article/VOL20-4/JPAE20_04_final.pdf\#page=89

Fink, L. D. (2013). Creating significant learning experiences: An integrated approach to designing college courses. John Wiley \& Sons.

Freire, P. (1985). The Politics of education. New York: Bergin \& Garvey.

Gewin, V. (2004). Mapping opportunities. Nature, 427(6972), 376-377. http://dx.doi.org/10.1038/nj6972-376a

Gibbons, M. (1998). Higher Education Relevance in the 21st Century. Washington DC: World Bank.

Goldberg, E. S., \& Greenberg, D. (2004). What's a Cultural Studies Curriculum Doing in a College like This? LIBERAL EDUCATION-WASHINGTON DC., 90, 16-25.

Gorski, P. (2000). Toward a Multicultural Approach for Evaluating Educational Web Sites. Multicultural 
Perspectives, 2(3), 44-48. http://dx.doi.org/10.1207/S15327892MCP0203_11

Hofstede, G. (1982). Culture's Consequences: International Differences in Work-Related Values, Cross-Cultural Research and Methodology Series (Vol. 5). London: Sage Publications.

Holmes, R. M., Liden, S., \& Shin, L. (2013). Children's Thinking Styles, Play, and Academic Performance. American Journal of Play, 5(2), 219-238.

Hope, C. B., \& Peterson, C. A. (2002). The sum is greater than the parts: Cross-institutional collaboration for information literacy in academic libraries. Journal of Library Administration, 36(1-2), 21-38. http://dx.doi.org/10.1300/J111v36n01_03

Huizinga, J. (1938/1955). Homo ludens: A study of the play element in culture. Boston: Beacon Press.

Jacobs, H. H. (1989). Interdisciplinary curriculum: Design and implementation. Association for Supervision and Curriculum Development, 1250 N. Pitt Street, Alexandria, VA 22314.

Jacobs, J. A., \& Frickel, S. (2009). Interdisciplinarity: A critical assessment. Annual Review of Sociology, 35, 43-65. http://dx.doi.org/10.1146/annurev-soc-070308-115954

Jarrett, O. S., \& Burnley, P. (2010). Lessons on the role of fun/playfulness from a geology undergraduate summer research program. Journal of Geoscience Education, 58(2), 110-120. http://dx.doi.org/10.5408/1.3534844

Johnson, L., Adams, S., Cummins, M., Estrada, V., Freeman, A. \& Ludgate, H. (2013). The NMC Horizon Report: 2013 Higher Education Edition. NMC

Jonassen, D. H. (1999). Designing constructivist learning environments. Instructional design theories and models: A new paradigm of instructional theory, 2, 215-239.

Karsten, L. (2002). Mapping childhood in Amsterdam: The spatial and social construction of children's domains in the city. Tijdschrift voor economische en sociale geografie, 93(3), 231-241. http://dx.doi.org/10.1111/1467-9663.00199

Marfo, K., \& Biersteker, L. (2011). Exploring culture, play, and early childhood education practice in African contexts. In S. Rogers (Ed.), Rethinking play and pedagogy in early childhood education: Contexts, concepts and cultures (pp. 73-85). London: Routledge.

Marsh, K. M. (2008). The musical playground: Global tradition and change in children's songs and games. Oxford: Oxford University Press.

McCurley, K. S. (2001). Geospatial mapping and navigation of the web. In Proceedings of the 10th international conference on World Wide Web (pp. 221-229). New York, NY: Association for Computing Machinery(ACM). http://dx.doi.org/10.1145/371920.372056

McLellan, H. (2007). Digital storytelling in higher education. Journal of Computing in Higher Education, 19(1), 65-79. http://dx.doi.org/10.1007/BF03033420

Mishra, P., \& Koehler, M. (2006). Technological pedagogical content knowledge: A framework for teacher knowledge. The Teachers College Record, 108(6), 1017-1054. http://dx.doi.org/10.1111/j.1467-9620.2006.00684.x

Moore, C., \& Woodrow, P. (1999). Mapping cultures: strategies for effective intercultural negotiations. Track Two: Constructive Approaches to Community and Political Conflict: Culture and Conflict, 8(1). R-11. http://www.mediate.com/articles/cdr1.cfmA

Noddings, N. (2013). Curriculum for the $21^{\text {st }}$ Century. In D. J. Flinders, \& S. J. Thornton (Eds.), The curriculum studies reader (pp. 399-405). Psychology Press.

Norris, K (2012). The use of digital storytelling for Reflection and Civic Growth. Indiana University-Purdue University Indianapolis Assessment Institute.

Ntelioglou, B. Y., Fannin, J., Montanera, M., \& Cummins, J. (2014). A multilingual and multimodal approach to literacy teaching and learning in urban education: A collaborative inquiry project in an inner city elementary school. Frontiers in psychology, 5(553), 1-10. http://dx.doi.org/10.3389/fpsyg.2014.00533

Robin, B. R. (2008). Digital storytelling: A powerful technology tool for the 21 st century classroom. Theory into practice, 47(3), 220-228. http://dx.doi.org/10.1080/00405840802153916

Roopnarine, J. (2010). Cultural variations in beliefs about play, parent-child play, and children's play: Meaning for childhood development. In A. D. Pellegrini (Ed.), The Oxford Handbook of the Development of Play. 
Oxford: Oxford University Press.

Rossi, D., van Rensburg, H., Harreveld, R. E., Beer, C., Danaher, P. A., \& Clark, D. (2012). Exploring a cross-institutional research collaboration and innovation: deploying social software and Web 2.0 technologies to investigate online learning designs and interactions in two Australian Universities. Journal of Learning Design, 5(2), 1-11. http://dx.doi.org/10.5204/jld.v5i2.108

Rouse, L. J., Bergeron, S. J., \& Harris, T. M. (2007). Participating in the geospatial web: Collaborative mapping, social networks and participatory GIS. In The Geospatial Web (pp. 153-158). Springer London. http:/dx.doi.org/10.1007/978-1-84628-827-2_14

Rubin, K. H. (2001). The play observation scale (POS). Center for Children, relationships and Culture. University of Maryland.

Schwartzmann, H. B. (1978). Transformations: The Anthropology of Children's Play. New York: Plenum.

Shepherd, M. (2004). Library Collaboration: What makes it work. In Proceedings of the 25th IATUL Annual Conference (Vol. 14, pp. 1-11).

Sinton, D. S. (2009). Roles for GIS within higher education. Journal of Geography in Higher Education, 33(S1), S7-S16. http:/dx.doi.org/10.1080/03098260903034046

Sutton-Smith, B. (1986). Toys as culture. New York: Gardner.

Sutton-Smith, B. (1997). The ambiguity of play. Cambridge, MA: Harvard University Press.

Van Dusen, G. C. (1997). The Virtual Campus: Technology and Reform in Higher Education. ASHE-ERIC Higher Education Report, 25(5).

Veitch, J., Salmon, J., \& Ball, K. (2008). Children's active free play in local neighborhoods: A behavioral mapping study. Health education research, 23(5), 870-879. http://dx.doi.org/10.1093/her/cym074

Wink, J. (2010). Critical Pedagogy: Notes from the Real World (4th ed.). Upper Saddle River, NJ: Prentice Hall.

Wyatt, J. B., \& Bloemker, G. A. (2013). Social and Emotional Learning in a Freshman Seminar. Higher Education Studies, 3(1), 106-114. http://dx.doi.org/10.5539/hes.v3n1p106

Yang, Y. T. C., \& Wu, W. C. I. (2012). Digital storytelling for enhancing student academic achievement, critical thinking, and learning motivation: A year-long experimental study. Computers \& Education, 59(2), 339-352. http://dx.doi.org/10.1016/j.compedu.2011.12.012

\section{Note.}

Note 1. All incoming students to the University take the web-based strengths finder assessment. The StrengthsQuest experience starts with the Clifton StrengthsFinder, a web-based assessment based on the principles of positive psychology. Upon completion of the assessment, individuals are given their top 5 Signature Themes of Talent as a starting point for self-discovery. Specifically, StrengthsQuest provides students, faculty and staff the information, tools and resources to help an individual, a program or an entire campus achieve academic, career and personal success.

\section{Appendix A: DIGITAL STORYTELLING MAP}

The digital interactive map with linked stories is a reflexive and recursive representation of your playtime among children or adults. The map highlights neighborhoods selected, and geo-spatially situated different forms of arts play. We will use the area captured below as our starting point for developing our maps and then stories within the map. 


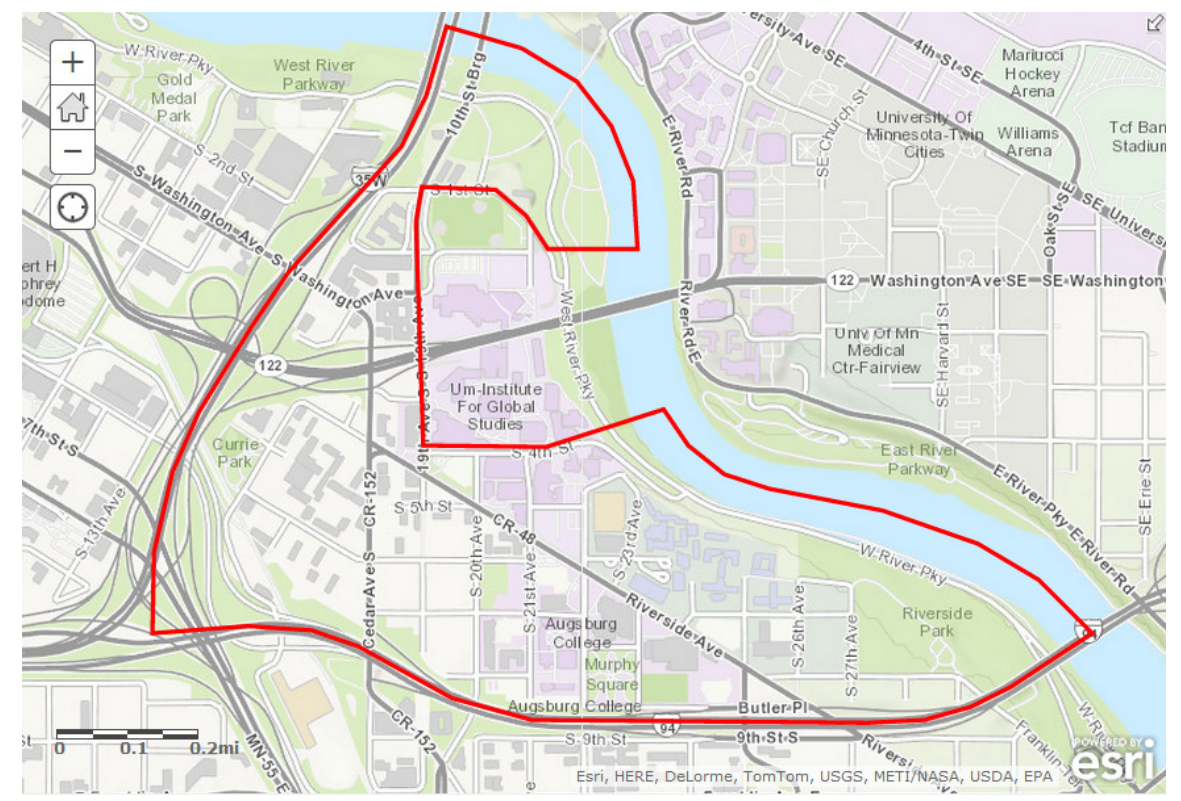

Figure 1. Cedar Riverside Neighborhood in Minneapolis, Minnesota

Directions: You have 300-500 words to tell a story about play that is engaging. Reflect on your observations and interview. Identify the games and stories about play you would like to include on the digital map. Your digital map will require that you set the context for your observation or interview (using text, audio, images, and music to communicate something about the culture) and edit your video to capture the essence of the play event. Select video and pictures and place on the digital map with an explanation of where the picture and what is happening in the picture. Why is this play significant? Add your initials at the end of each caption.

Organize the map highlighting neighborhoods selected. When a user clicks on a neighborhood, a story or two about play in that neighborhood should emerge. Provide a short note indicating roles you played in designing the digital map.

Evaluation Criteria: (Adapted from Gorski, P. (2000). Toward a Multicultural Approach for Evaluating Educational Web Sites. Multicultural Perspectives, 2(3) 44-48. Questions are also drawn from Catherine Solheim's digital story grading rubric for FSoS 3104 Global and Diverse Families.)

1. Relevance and Appropriateness (4 points): Is the map content relevant to the course? What is the mission and scope of the digital map? Are graphic images appropriate? Are faces of children blurred to protect their identity?

2. Purpose (4 points): Do you provide a clear explanation of the purpose of your digital story about two arts play events, who is being interviewed, and what the story is about?

3. Context (4 points): Do we understand the cultural context of the children's arts play? Are images, text, music, etc. effectively used? Are citations accurate and appropriate?

4. Content (4 points): Is the essence of the interviewee's arts play captured? Are we able to get a glimpse into cultural influences on play?

5. Quality (3 points): Is your digital story visually clear, engaging, and audible? Does your story use a conversational style throughout?

6. Credibility-citations 2 point): Are author roles of the site clearly indicated? Are citations present and sound credited?

7. Accessibility (1 point): Is contact information provided for the map?

8. Economy (2 points): Is the story told with exactly the right amount of detail and in time (3-4 minutes)

9. Navigability (2 points): Is map organization simple and obvious? Do navigation bars or prompts allow users to navigate to access digital stories in different places on the map? 


\section{Children's play (4 points):}

Does the map...

a. Use a variety of media and styles to effectively engage viewers?

b. Encourage interaction between author and viewer-users or among users?

c. Capture intercultural perspectives on play through captions?

d. Invite critical examination or diverse perspectives by giving voice to other play perspectives in images, text and music?

\section{Appendix B: Week-by-Week Schedule: Mapping art play in the Twin Cities}

\section{Week 1: Defining play, personal play and arts play (September 4, 2013)}

Goals: In this session, participants will:

- Review course syllabus and class expectations.

- Discuss the thought systems informing play, and arts play, that is why play?

- Conventions on the rights of the child to play

- Find out who are we together, build a learning community among classmates and share strengths

- Share our games

\section{Week 2: Culture and play (September 9, 11 \& 13)}

Goals: In this session, participants will:

- Define play in personal and collective culture to discover our cultural diverse perceptions of play (gender and social class)

- Define and discuss globalization and its impact on the play.

- Explain conceptual frameworks for play?

- Explore the process of asking questions about play?

- Discuss intersection of culture, play, globalization and their impact on personal play lives.

- Attend library tutorial session with Timothy Maloney, Music Librarian, University of Minnesota

\section{Week 3: Folklore and Play (September 16, 18, \& 20)}

Goals: In this session, participants will:

- Analyze the interrelationship of folklore and arts play

- Determine how gender, social, cultural, biographical and the political impact the choices children make about play

- Discuss the interrelationships among the arts expressions in play

- Describe how children incorporate play into their daily lives, rituals and ceremonies, and its role in coping, healing, and problem-solving

- Identify places for play in the Twin Cities: Looking for Currie Park

\section{Week 4: Perceptions, Patterns and Processes: Mapping (September 23, 25 \& 27)}

Goals: In this session, participants will:

- Dialogue with Professor, University of Minnesota Crookston Campus

- Discuss mapping as a digital visual of arts play observations.

- Explore digital mapping software with Dr. Justin Schell, University of Minnesota Libraries

- Explore digital Storytelling software

- Walking the Cedar Neighborhood district- Murphy Park and Svea Triangle

\section{Week 5: Where Children play: The Dumps, Train Tracks and Polluted Water (Sept. 30, Oct 2. \& 4)}

Goals: In this session, participants will:

- Plan and designing places for play- Lab work 
- Identify places for play in the Twin Cities (Riverside Park)

- Write and talk play environment analysis or observation.

- Discuss safety issues for play and recreation

- Outline guidelines for safe and accessible play environments for all according to ADA, ASTM and CPSC.

- Create Observational Checklist

- Play at housing projects, and recreational sites.

\section{Week 6: Where Children play: The ethics of observing in intercultural contexts (October 7, 9, \& 11)}

Goals: In this session, participants will:

- Discuss stereotypes and generalizations about play behavior in story telling

- Review first journal requirements.

- Discuss the cultural, universal and personal in intercultural play communication

- Identify and understand skills required for play leadership and quality of play stories

- Discuss doing observations, representation and ethics in play work

- Play in the neighborhood: Participant Observations at Riverside and Currie Park

\section{Week 7: Asking children questions: Intercultural Context (October 14, 16, 18)}

Goals: In this session, participants will:

- Identify the qualities for play leadership toward, advocacy, and service on the importance of play

- Focusing our projects

- Develop interview questions, legal and ethical issues

- Discuss "truth" in conducting interviews about play

- Address the difference between verbal and nonverbal intercultural play communication

- Participate in play in the neighborhood: Taking pictures at the park

\section{Week 8: Performing Arts Play (October 21, 23 \& 25)}

Goals: In this session, participants will:

- Identify key players and areas for project

- Review steps in Digital storytelling process

- Review Interview list

- Describe the impact of the observation experience on understanding choices people make about play

- Create a storyboard

- Play with and learn from children in selected Twin Cities area

\section{Week 9: Analyzing Arts Play Interdisciplinary Positions (October 28, 30, \& November 1)}

Goals: In this session, participants will:

- Review Interviews Critically analyze how cultural perspectives inform arts play expression.

- Critically analyze how specific disciplines inform arts play expression

- Visit Social Welfare History Archives of Elmer Andersen Library for historical information on play with Linnea Anderson, Elmer Andersen Library

- Situate cultural perspectives in arts play in play spaces:

- Observations or Library/Archival work on your own

\section{Week 10: Questioning Arts Play: Adults in Children's Play (November 4,6, \& 8)}

Goals: In this session, participants will:

- Review interview transcripts, Analyze interviews and observations, Finding themes

- Define the role of adults in promoting or inhibiting play

- Engage children in conversations about the role of adults in their play 
- Determine variations in adult roles in arts play on specific play spaces.

- Dialogue about digital storytelling with Scott Spicer, Media Outreach Spaces Librarian, UMN

- Interviews or Library/Archival work on your own

\section{Week 11: Mapping Play (November 11, 13, 15)}

Goals: In this session, participants will:

- Revisit dialogue about digital mapping with Professor, UMN, Crookston Campus

- Synthesize stories gathered in the field

- Discuss representation on Digital Story

- Create Digital Story

\section{Week 12: Mapping Digital Play Stories (November 18, 20, 22)}

Goals: In this session, participants will:

- Finalize script

- Review Ethics and citations-Literature and pictures

- Watch digital stories and discuss representation of story on Digital Map

- Dialoguing with GIS students

- Record narration and send link to mappers

\section{Week 13: Finalizing Stories in Maps (November 25, 27)}

Goals: In this session, participants will:

- Review the details of preparing the final digital project/ and rubrics

- Assess play transformations and our Strengths

- Revise rough edit and create final story

- Share stories with play friends and friendship groups for revisions

\section{Week 14: Arts Play in Our Lives (December 2,4, 6)}

Goals: In this session, participants will:

- Discuss ethics of representing self and another through stories about arts play and play

- Acknowledge personal, cultural, intellectual transformations connect to Strengths.

- Connect the digital to the real-physical - play in our lives

- Discuss the impact of play in the neighbor on lives of participants, and academic self.

- Outline program/ posters for program

- Invite friends to presentation

\section{Week 15: Presentation of Project and Reflections. (December 9)}

Goals: In this session, participants will:

- Share stories with play friends and friendship groups

- Present their projects, and reflections

\section{Copyrights}

Copyright for this article is retained by the author(s), with first publication rights granted to the journal.

This is an open-access article distributed under the terms and conditions of the Creative Commons Attribution license (http://creativecommons.org/licenses/by/3.0/). 